\title{
Especialidades Médicas - Geriatria
}

\author{
Elina Lika Kikuchi
}

Todos sabem que o mundo e o Brasil estão envelhecendo... E todos almejam a longevidade, não somente com anos de vida a mais, mas também acompanhada de qualidade de vida. $\mathrm{Na}$ prática médica após a sua formação, os estudantes encontrarão os idosos como um grande percentual de sua clientela (exceto na pediatria e na obstetrícia). Precisamos entender que essa população necessita de um olhar diferente do adulto jovem, com atenções específicas, formas de avaliação e tratamento diferenciados.

A Geriatria refere-se à especialidade médica responsável pelos aspectos clínicos do envelhecimento e pelos amplos cuidados de saúde necessários às pessoas idosas. É a área da medicina que cuida da saúde e das doenças da velhice; que lida com os aspectos físicos, mentais, funcionais e sociais nos cuidados agudos, crônicos, de reabilitação, preventivos e paliativos dos idosos; e que ultrapassa a "medicina centrada em órgãos e sistemas" oferecendo tratamento completo, em equipes interdisciplinares e com o objetivo principal de otimizar a capacidade funcional e melhorar a qualidade de vida e a autonomia dos idosos

A Geriatria como especialidade médica, embora cuide de uma população de faixa etária mais velha (o idoso é definido como indivíduo com 60 anos ou mais pela Organização Mundial de Saúde) é relativamente nova. Ainda que tenha iniciado nos Estados Unidos e na Europa na década de 40, só começou a ser introduzida no Brasil na década de 70.

O Serviço de Geriatria do Hospital das Clínicas da Faculdade de Medicina da Universidade de São
Paulo (SGHCFMUSP) foi fundado em abril de 1982. Neste ano de 2012, junto com a comemoração dos 100 anos da Faculdade de Medicina da Universidade de São Paulo, o SGHCFMUSP está completando 30 anos.

A Residência Médica em Geriatria tem dois anos de duração, apresenta como pré-requisito dois anos de Residência Médica em Clínica Médica e atualmente conta com 12 vagas no SGHCFMUSP.

O Geriatra após o término da Residência Médica pode atuar em diversas áreas, como:

- consultório ou ambulatório, atendendo consultas ambulatoriais;

- hospitais, acompanhando seus próprios pacientes internados ou realizando interconsultas para outras especialidades (principalmente cirúrgicas), ou ser contratado como internalista, para cuidar de pacientes internados em determinado hospital (lembrando que os idosos são a população que mais interna e com mais gastos hospitalares);

- atendimento domiciliar, para atendimento de idosos com grau de dependência maior, que tem dificuldade em ir até o consultório e que não tem indicação de internação hospitalar ou que devem evitá-la pelo risco de complicações;

- instituição de longa permanência para idosos, para realizar acompanhamento de idosos institucionalizados;

- programas de promoção em saúde, para avaliação clínica, solicitação de exames complementares pertinentes e recomendações adequadas para a promoção de saúde;

Médica Assistente do Serviço de Geriatria do Hospital das Clínicas da FMUSP. 
- saúde pública, para assistência do idoso em atenção secundária ou terciária e coordenação de ações voltadas para a saúde da população idosa;

- hospital-dia geriátrico, para acompanhamento de pacientes que necessitam de internação hospitalar durante o dia para realização de avaliação, procedimentos diagnósticos, terapêuticos ou reabilitação e não necessariamente uma internação hospitalar tradicional que apresenta mais gastos e complicações;

- gerenciamento de pacientes crônicos, geralmente para empresas de saúde privada para garantir controle e tratamento de doenças, evitando complicações e maior gasto financeiro com esses pacientes;

- cuidados paliativos, para garantir conforto e alívio de sofrimento quando o paciente apresentar enfermidades graves e incuráveis;

- carreira acadêmica como professor universitário, para ensinar alunos, médicos e outros profissionais de saúde sobre envelhecimento e cuidados com idosos e pesquisa na área do envelhecimento.

A satisfação com a especialidade é muito grande, principalmente relacionada com a melhora que podemos obter em termos de qualidade de vida dos pacientes e familiares e o reconhecimento desse impacto pelos mesmos, visto que a maioria das doenças que conhecemos são crônicas e incuráveis.

$E$ isso é obtido com uma avaliação adequada (Avaliação Geriátrica Global), diagnósticos corretos e tratamentos que levam por vezes à suspensão de medicamentos, os quais podem ser a causa dos sintomas do paciente. Dizemos que uma das coisas que o geriatra mais gosta é retirar medicações de seus pacientes. É muito gratificante verificar que muitas vezes medidas simples podem melhorar muito os sintomas clínicos do paciente, além de sua autonomia (capacidade de poder comandar a própria vida) e independência (capacidade de realizar algo com seus próprios meios, sem necessitar de ajuda de outras pessoas).

Em relação à remuneração do geriatra, o salário é variável dependendo do tipo e local de atuação e do tempo disponibilizado para o trabalho.

\section{Mitos e preconceitos em relação à especialidade}

Existem alguns preconceitos relacionados ao desconhecimento do papel efetivo do geriatra.
Muitos o vêem como o profissional que "apenas cuida bem do idoso e prescreve vitaminas". É claro que é um preceito da medicina cuidar bem de seus pacientes e o geriatra também o faz. Embora venha com um ar pejorativo, sempre que houver a possibilidade de melhora na qualidade de vida de um indivíduo idoso com a implementação de ações estruturadas e cientificamente comprovadas, estas serão realizadas.

Com o envelhecimento populacional crescente temos vários mitos relacionados à procura do elixir da juventude ou da longa vida ou ainda do combate ao envelhecimento. Sabemos que o envelhecimento é uma fase da vida que praticamente todos os seres vivos passam e a única forma de combatêlo seria morrendo antes de chegar nesta etapa da vida. O geriatra precisa saber quais intervenções são benéficas e quais não tem ação comprovadas, mesmo sendo muito propagadas na mídia (como os polivitamínicos) e, que ainda podem trazer efeitos adversos.

É importante ressaltar que Geriatria não é Clínica Geral de idosos, assim como a Pediatria não é Clínica Geral de crianças. Existem diversas diferenças entre idosos e adultos jovens que envolvem desde o que é senescência (processo natural de envelhecimento) e senilidade (processo patológico do envelhecimento), até na apresentação clínica das doenças (geralmente atípica em idosos), nas peculiaridades do tratamento farmacológico na população idosa e da importância da promoção de saúde e da reabilitação nessa faixa etária.

\section{Dificuldades}

Assim como em qualquer especialidade, encontramos algumas dificuldades como:

- a duração da consulta é mais longa (30 a 60 minutos), o que pode comprometer os honorários quando vinculados ao número de atendimentos;

- necessidade de equipe interdisciplinar para auxílio no diagnóstico e tratamento, nem sempre disponível;

- lidar com pacientes com doenças avançadas, com conflitos familiares ou com falta de suporte social.

\section{Conclusão}

O geriatra reconhece a interdependência das condições clínicas, sociais e psicológicas na saúde 
geral de seus pacientes e cuida do idoso e não apenas de suas doenças.

O geriatra, diferente dos especialistas, tem a visão do idoso como um todo e principalmente para aquele indivíduo portador de várias doenças, consegue saber priorizar o que é mais importante para o paciente naquele momento. Ele deve ter um conhecimento amplo das recomendações científicas, mas deve saber elencar os riscos e benefícios dessas estratégias para aplicar naquele indivíduo idoso específico, pensando nas consequencias para o futuro.

Além disso, um dos principais papéis do geriatra é coordenar múltiplos tratamentos, para que um não prejudique o outro, por vezes com o auxílio de outros especialistas e outros profissionais de saúde.

O geriatra vê o idoso como um todo hoje, mas de olho no amanhã. 